\title{
Designing an Effective e-Content Development Framework for the Enhancement of Learning Programming
}

\author{
http://dx.doi.org/10.3991/ijet.v11i04.5574 \\ Meysun Hamdi and Thair Hamtini \\ The University of Jordan, Amman, Jordan
}

\begin{abstract}
This article presents an ongoing research project on the development of e-content in relation to the cognitive theory of multimedia learning. Previously, a literature review has been conducted on e-content development models, the cognitive theory of multimedia learning, and the problems encountered while learning computer programming. In this work a new framework is proposed for the development of e-content. An experiment was conducted in the Jubilee Centre for Excellence in Education among (98) secondary school studentsin order to assess the value of a Proposed Framework that uses the Cognitive Theory of Media Learning. The study sample was divided into two groups, One group studied computer programmingusing e-content Based on the Behavior Change Techniques using the Proposed Framework (BPF), and the other group studied computer programming based on e-content that was Not Based on the Proposed Framework (NBPF). The students' performance was assessed by a pre-test grading scale and a post-test and an analysis made using Statistical Package for the Social Sciences (SPSS). The results showed that the students who studied computer programming through BPF achieved better scores than the students who studied computer programming through NBPF. Therefore, applying the cognitive theory of multimedia learning properly at the same conditions, as applied in this study in the educational process will significantly reduce the cognitive overload associated with learning through multimedia elements and improve student achievement.
\end{abstract}

Index Terms-Learning Programming, Cognitive Theory of Multimedia Learning, e-Content Development, Educational Design, Educational Technology.

\section{INTRODUCTION}

The learning process has been influenced by the expansion and evolution of computer, network, and multimedia technologies. Those technologies allow the learners to participate in an active and self-paced learning environment. Technologies were not necessarily changing the way of teaching subjects. What has changed in fact is the discipline of teaching resources at the teachers' and learners' behavior. They have added interest to the course content and delivery [1][2].

As the content industry is moving toward developing a highly interactive multimedia learning content, most webbased contents have been developed using text, image, sound, and video, but failed to induce interactivity contents [3].

Therefore, the ability to construct effective, useful, useable, and satisfying electronic contents remains one of the major obstacles in e-learning because the educational design is complex, and the main aim of developing econtent is to achieve specified goals in education, and place the learner needs at the center of the learning process [4][5].

Today, the cognitive approach is developed which is in essence rationalist. It have emerged significantly trying to understand human beings and their ability to process incoming new knowledge. The cognitive theory of multimedia learning interprets that learners have dual information transformation channels; visual and verbal that divide the processing work. Where audio is transferred through the verbal channel. Text $\&$ graphics are transferred through the visual channel. Both visual and verbal channels influence learner attention, and both channels in multimedia learning must be structured in a way to be harmonious to maximize the learning process [6][7].

Cognitive theory of multimedia learning suggests that the learning process through graphics increases learning abilities and applying the cognitive science method to the contents increases the learners' interest in the learning process. However, humans are limited in the amount of information that can be transferred in each channel at one time when dealing with new knowledge. The constraints of the processing capacity force us to make decisions about which segments of information to pay attention to, the degree to which we should build connections between selected segments, and the learners' previous knowledge $[8][9][10][11]$.

For many years, words have been the major format for instruction; including spoken and printed words. Recently, pictorial forms of instruction are becoming widely available, but simply adding pictures to words does not ensure improvement in learning -that is, not all multimedia presentations are equally effective [12].

Until now, much of what have been developed in multimedia instructional design and e-contents appears to be based more on anticipation rather than empirically based research [11]. In addition, Instructional design which proceeds without indication to human cognition is likely to be random in its effectiveness [13].

Although, many researchers have made huge progress in establishing the cognitive theory of multimedia learning and its principles for improving the quality of learning, there is still much to be done; such as integrating the different theories of multimedia learning, and building a reasonable research base. More work is needed to understand the basic structures in theories of multimedia learning, to generate testable predictions from the theories of 
multimedia learning, and to test these predictions in strict scientific experiments. The best way to ensure the effectiveness of the theories of multimedia learning is to have concrete research literature on which to base them [10]. Therefore, a research should be conducted in order to make scientific advancement in the field of multimedia learning in e-contents, by studying how good oldfashioned learning essentials, and how the essentials in advanced technological artefacts affect the way in which individual learn [14].

\section{RESEARCH QUESTION AND HYPOTHESIS}

In this study, the researchers aim to determine the effects of applying the cognitive theory of multimedia learning on improving the academic achievement of the $11^{\text {th }}$ grade students in learning computer programming at the Jubilee Center for Excellence in Education in Jordan. The following Research Question was studied:

"Is it possible to come up with an e-content development framework to help e-course developers and designers produce an effective content that has the potential to improve student learning? What are the components of such a model?"

The following hypothesis wasbased on the Research Question:

"Designing and developing an e-content based upon the cognitive theory of multimedia learning will help reduce the cognitive overload associated with learning programming and will significantly improve students' learning."

\section{RELATED WORK}

There are many models, which were developed for different purposes related to courseware development $[8][15][16][17][18]$.

Azemi[15] discussed some of the foreseeable features of multimedia-based education in courseware development that are useful in active learning, and used these features in their'circuits' courseware product because they believed that the classroom lectures should be organized in a way to achieve active participation. Their model focused mainly on designing an effective learning tool by achieving active learning. Active learning in some cases can make cognitive overload. Therefore, it is very important to reduce the overload that can result from the learning environment in a way that supports active learning.

Kiili[19] presented a multimedia learning model that can be used in designing multimedia learning environments to support active learning process and creative participation. Theysuggested some types of contents including: interactive contents, executable contents, process contents, animation contents, and media-oriented contents, but their study failed to support the cognitive approach in which learners have limited capacity in their working memory and they cannot process all incoming knowledge.

Nie and Liu [18] mainly discussed the development, design and application of multimedia Computer-Aided Instruction (CAI) courseware in detail. They provided a four-step process: analysis of the plan, design, realization, use and maintenance. They also presented some requirements for making a multimedia courseware, and discussed the process of developing multimedia courseware. Finally, they provided a list of instructions for evaluating multimedia courseware.
Recently, many researchers studied the cognitive theory of multimedia learning and the cognitive load theory. They presented the principles that have been emerged recently to support the learning process and minimize the load on the working memory. They have made reductions on the cognitive load in multimedia-based instruction through some principles, but more reliable and valid principles are needed with a more empirically based research to support their assumptions and to guide instructional designers [20].

Mayer and Moreno [21] studied the experiments that where generated previously by Mayer to determine the major principles that can be used in a multimedia instruction to help students understand the presented knowledge. They reached to the fact that Multiple Representation Principle, Contiguity Principle, Split-Attention Principle, Individual Differences Principle, and Coherence Principle are very effective in reducing the cognitive overload in students' working memory and thus increasing knowledge.

Li et al.[22] suggests that multimedia elements should be used with an appropriate planning and careful consideration to achieve meaningful content arrangement. They selected to follow Mayer's Design Principles to achieve their learning goals. Their main concern in their study was to look at students' perceptions on the independent online learning, which is a student centered learning environment. They noticed that students' performances were improved and they have proven that students were motivated in the web-learning environment. However, as mentioned before, there is a need to more reliable and valid principles with a more empirically based research to improve student learning and guide instructional designers in building their own learning contents.

In addition to the previous studies, this research will take a further step to design a framework that focuses on enhancing and promoting teaching and learning of such difficult courses that create cognitive overload using the cognitive theory of multimedia learning.

Information Technology, e-learning and e-contents are currently used in various fields such as science, mathematics, languages and programming. The main reason for that is to improve learning of such difficult subjects and to find solutions for the issues concerned with these types of subjects. For example, computer programming is a difficult subject area, which put a heavy cognitive load on students working memory [23].

Previous literatures on e-learning system and courseware development have focused on the system features and on the different technologies employed. Courseware, just as any other software, needs a processbased analysis to understand its development. In addition, it needs to integrate both cognitive and technical issues during the design and implementation phases.

While various technologies are available for the development of educational contents, the effective use of a new instructional technology should be driven by researchbased pedagogical principles. Fortunately, advances in cognitive psychology provide the starting point for such theories to understand how multimedia technologies can be used to enhance student learning.

Instead, the challenge is to build a deep understanding of the relationship between technology and learning pro- 
cesses especially when developing a new technology that supports specific cognitive functions.

\section{A FRAMEWORKFOR DEVELOPINGAN EFFECTIVE COURSEWARE}

This section consists of three main dimensions, which were found in literature review regarding the field of econtent development. The learning environment, the user interface, and the course content. The various dimensions are integrated from various required disciplines within a framework of interrelated models. The proposed framework for developing an affective e-content is briefly outlined in Fig. 1 below.

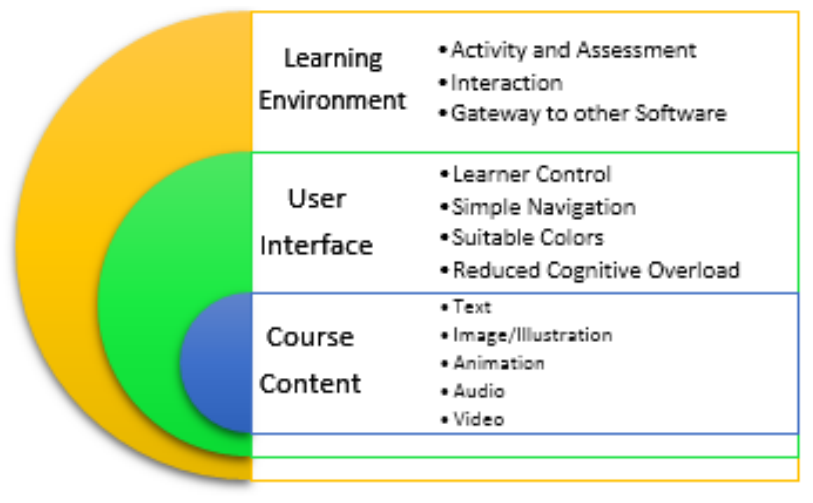

Figure 1. H\&H Framework

\section{A. Learning Environment}

Dillenbourg et al.[24]used the term learning environment in a very broad way, including for instance Web sites that include static Web pages. Some environments include less sophisticated interfaces, namely text-based. However, a set of Web pages cannot be specified as a learning environment unless there is social interaction about the information. Communication inside a learning environment can be categorized as direct and indirect. Direct communication includes synchronous (e.g. chat) versus asynchronous (e.g. electronic mail, forums), oneto-one versus one-to-many or many-to-many, text-based versus audio and video. Indirect communication can be done by sharing objects.

Learning environments may support navigation and learning activities. In Web-based environments, learning activities range from multiple-choice questions to problem solving. Simulations are indeed learning environments as well.

A learning environment integrates a variety of tools supporting multiple functions: learning activities, interaction, assessment, and navigation. Therefore, the idea of environment includes the concept of integration.

One of the main obvious opportunities of learning environments is that they support communication in many ways. However, some teachers believed that when their students use e-mail, they would start to ask smart questions about the content or the learning material, but actually most email conversations from students were about the management of learning such as finding resources, negotiating deadlines and asking for an appointment. The major problem is not due to the technology, but to the educational content and its design. Therefore, designers of an econtent have to develop a better understanding of the relationship between how information is structured and how it can be used in learning activities and interactions.

According to that, a learning environment must contain the following components:

\section{1) Activity and Assessment}

Shepard [25] defined assessment as a part of an effort to improve the quality of education. Assessment in education must be used to help students learn and to improve learning rather than be used to rank students learning, where students perform to get good grades rather than to achieve a compelling purpose. Therefore, assessment has to occur in the middle of the learning content, not just at the end, and must focus on learning processes not just outcomes.

One of the most obvious assessment methods is the use of open-ended (essay) questions to ensure that students are able to think critically, solve complex problems, and apply their knowledge in real-world cases. Fill-in-the-blank, short-answer, or multiple-choice questions may also be useful in examining certain kinds of practical knowledge. It is also possible to use formal and informal assessment methods, with the balance between the two, considering students' age. In addition, using a variety of tasks, for both instruction and assessment, is also important for understanding new concepts. Students are more likely to understand and apply knowledge in new situations if they are presented with a set of problems, and encouraged to draw connections between them.

According to what discussed above, assessments should contain challenging tasks to formulate higher order thinking, address learning processes as well as learning outcomes, be an on-going process integrated with instruction, be used formatively in support of student learning, support feedback, and be used to evaluate student learning.

\section{2) Interaction}

Hill et al. [26] identified four types of interactions in a Web-based learning environment: learner-instructor interaction, learner-learner interaction, learner-content interaction, and learner-interface interaction.

Learner-interface and learner-content interactions are discussed in details under the titles 'User-Interface' and 'Course Content' in the following sections.

\section{3) Gateway to other Software}

Every learning environment contains some components such as activity and assessment, user-interface, and learning content. However, it should also provide other services such as a gateway to other software (i.e. some subjects need to be studied using computer based software such as learning programming to test the codes and run some programs in a programming environment). Therefore, providing some form of buttons to link other software to the learning environment can enhance students' learning of the subject matter especially for difficult subjects [15].

\section{B. User Interface}

The design of user interface in an e-learning environment has a special importance. Some learners spend lots of their time in trying to understand the navigational system rather than the learning content and this can result in wasting their time without reaching the specified learning goals. Therefore, it is necessary to follow some essential principles to design an effective user interface in an elearning system. The main aim of designing an effective 
user interface is to create an environment for the learner to successfully navigate through the learning material and gain understanding of the presented content [27].

An interface should provide the learners with information in what position they are placed and what are they doing, to decline the time duration needed for processing information not related to the learning content, and exclude any text or images that are not related to the learning content.

\section{Course Content}

The multimedia learning hypothesis in cognitive theory of multimedia learning suggest, "People can learn more deeply from words and pictures than from words alone". For many years, words have been the major format for instruction; including spoken and printed words. Recently, pictorial forms of instruction are becoming widely available, but simply adding pictures to words does not ensure improvement in learning -that is, not all multimedia presentations are equally effective [12].

Therefore, the development of an educational electronic content as any other software requires starting with the analysis, design, implementation, and testing phases and producing a product according to some principles of multimedia learning to reduce the cognitive overload resulting from some kinds of difficult subjects. Fig. 2 below shows the proposed e-content development lifecycle, and the following sections contain a detailed representation of each phase including some guidelines for developing an effective e-content.

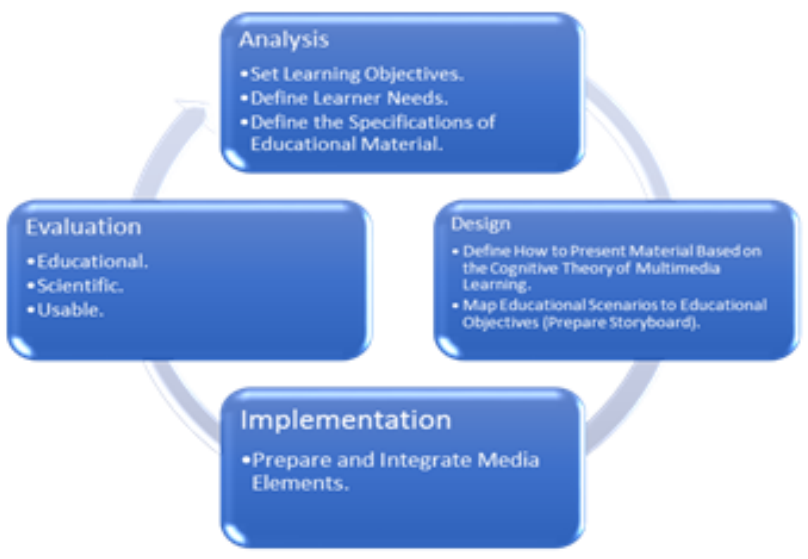

Figure 2. E-Content Development Lifecycle

\section{1) Analysis}

The first step in the development lifecycle of an educational electronic content is to analyze the requirements of a course content. Every single step included in the analysis phase is illustrated in details below.

\section{a) Set Learning Objectives}

Clearly defined learning objectives can guide the developers of an e-content to select the activities of teaching and learning, and authorize learners to be responsible of their own learning in a way that meets the expectations of e-content developers. When the learners know exactly what they are supposed to learn from the beginning of the learning process, they can gain responsibility of their own learning and are more likely to succeed.
The objectives of a course should be complete, appropriate, sound, feasible, relevant, open-ended, and be shared with students [28].

\section{b) Define Learner Needs}

It is very important that teachers respect learners and consider their perspectives. As discussed in McCombs [29], quality learning is learning that engages learners, and encourages discovery, creativity, and imagination. In addition, the course material needs to be shaped by what adults know and by students interests and their learning preferences.

Therefore, the course content should be presented in a way that allows for knowledge constructing rather than response strengthening or information acquisition, provide instructional support and guidance to allow learners create meaningful representations of knowledge, increase learner motivation by using game-like exercises moderately, and allow creativity, allow learners to participate as thinkers, provide interaction, and provide activity and assessment.

\section{c) Define the Specifications of Educational \\ Material}

The third step in the analysis phase of content development lifecycle is to define the specifications of educational material such as content and teaching methodology. Identifying 'content' means selecting the most suitable graphics for each content type. Identifying 'teaching methodology' means selecting the most effective methods in order to achieve learning goals.

\section{Identifying 'Content'}

In e-Learning, a combination of text, audio, still and motion visuals can be used to communicate the presented material. The use of words and graphics together in any presentation is better than using words alone. However, not all graphics are equally helpful in supporting learning. Decorative graphics, representational graphics, relational graphics, organizational graphics, transformational graphics, and interpretive graphics are some possible graphics that can be selected to present the material [30].

Clark (as cited in [30]), identified five different types of content: fact, concept, process, procedure, and principle. Each content type can be presented using the graphic types listed above. So for example Representational Organizational Graphics could be used to teach 'Fact' which a content type. Representational and Organizational graphics could be used to teach 'Fact' and 'Concept' content types. Transformational graphics could be used to teach 'Process', 'Procedure' and 'Principle' content types. Interpretive graphics could be used to teach 'Concept', 'Process' and 'Principle' content types. Relational Graphics could be used to teach 'Process' content type.

In addition to the content types listed above, the development of electronic contents may also contain interactive, and animation contents to allow learners participate in an active learning environment [8]. Fadel and Dyson[31] represented that the use of animation while presenting a series of steps helps the learners achieve the specified goals in learning. They have also suggested that providing text, which is relevant to the animation in a synchronous way, is more effective than presenting animation alone.

Interactivity in contents is an efficient way to help learners understand abstract concepts. It helps learners control a virtual circumstance to display results and gain 
understanding of a given concept. It also allows learners to control and confirm results immediately on the screen [8].

\section{Identifying 'Teaching Methodology'}

Different teaching methods can be used in education. The selected method depends mainly on the learning objectives, then on the technological resources available. To make learning meaningful, students should become active participators and engaged in their own learning [32]. Student-centered approaches should be used in order to achieve active participation, and this could be done using inductive teaching methods. Inductive teaching methods uses a strategy, which is known as 'noticing' where students are given multiple examples and are intended to notice how a concept works. Below are some kinds of teaching methods, which provide active participation [33].

Inquiry Learning: The learning process starts with providing learners with some questions, problems, and a set of observations. According to that, learners need to answer the questions, solve the problems, and explain the observations.

Problem-Based Learning: This type of teaching methods is the most complex and difficult to implement. Problem-based learning consist of complex, open-ended, and real-world problems; which require knowledge and skills specified in the learning objectives.

Project-Based Learning: The learning process starts with providing learners with an assignment to perform some tasks in order to develop a product. The product could be a design, a model, a device or a computer simulation.

Case-Based Teaching: Can be used when learning objectives involve making decisions in complex conditions and situations.

Discovery Learning: Discovery learning uses inquirybased learning where learners answer some questions, solve some problems, and explain some observations and then work in a self-directed way for discovering the desired knowledge. Learners then are provided with feedback on their effort without any guidance on how to find conclusions.

The teaching methods discussed above provide active participation because learners can be meaningfully engaged in the learning activities through the interaction with the learning tasks.

\section{2) Design}

The second step in the development lifecycle of an educational electronic content is the design phase. Every single step included in the design phase is illustrated in details below.

\section{a) Define How to Present Content Based on the \\ Cognitive Theory of Multimedia Learning}

Multimedia represents a powerful learning technology that have the ability to enhance human learning. Two main types of multimedia applications could be used; applications that present information to the learners, and applications that provide feedback on the correctness of learner answers on some problems [34].

Multimedia learning environments provide amazing possibilities for supporting a wide variety of learners. However, many researchers tried to find the most powerful technology that may enhance the quality of learning and on how to design interactive multimedia representations in virtual reality (the focus was almost on ' $\mathrm{e}$ ' rather than 'Learning'). Actually, we must not forget the importance of technology in enhancing the quality of learning but moderation in the use of technology is more effective and can achieve better results in learning [35].

It is necessary to understand the possible risks that may result from new technologies in order to limit their negative influence on learning [35]. For this reason, an econtent should be developed according to human cognition rather than to the available technological resources [34].

The main issue in learning is that learners have difficulties in carrying out multiple processes in both channels of working memory due to the limits concerned with each channel. There are three important aspects for cognitive processing capacity, which could be managed to achieve learning goals that are extraneous processing, essential processing, and generative processing [30].

According to Mayer [36], the main aim of multimedia learning is to manage essential processing, decrease extraneous processing and encourage generative processing. Table I below links each aspect of cognitive processing capacity with multimedia principles that have the ability to reduce, manage and encourage each processing.

TABLE I.

Multimedia Principles to MANAge Cognitive Processing

\begin{tabular}{|l|l|}
\hline \multicolumn{1}{|c|}{ Cognitive Processing } & \multicolumn{1}{c|}{ Multimedia Principles } \\
\hline $\begin{array}{l}\text { Reducing Extraneous } \\
\text { Processing }\end{array}$ & $\begin{array}{l}\text { coherence, signalling, redundancy, spatial } \\
\text { contiguity, temporal contiguity }\end{array}$ \\
\hline $\begin{array}{l}\text { Managing Essential Pro- } \\
\text { cessing }\end{array}$ & segmenting, pre-training, modality \\
\hline $\begin{array}{l}\text { Encouraging Generative } \\
\text { Processing }\end{array}$ & multimedia, personalization, voice, image \\
\hline
\end{tabular}

As discussed before, there must be a criterion for presenting content to fully attract learners to the learning content and achieve learning goals. Below are some guidelines for presenting text, images or illustrations, audio, animation, and video.

\section{How to Present Text?}

Verhoeven and Perfetti [37] suggested that mixing up some components of multimedia could facilitate teaching of such text as denoted in Mayer's cognitive theory. They tried to find a way in order to present multimedia text to improve learners' reading experience. They added that all the fundamental models that where generated for teaching text, have shown that understanding couldn't be achieved only by written on-screen text. In addition, adding other components to the written on-screen text allow the learners make connections about what is in the text based on their previous knowledge.

Fletcher and Tobias [20] stated that the use of pictures with words is more effective than using words alone. In addition, Mayer and Moreno [21] stated that students could achieve better results when they watch and listen than when they just watch.

As a conclusion to what have been studied by researchers on the principles of multimedia learning, the presentation of text should be provided using the guidelines, which are presented below. 
- If the presented text explains other kind of visuals, such as images, animation or video, it is better to convert it to an audio format and remove the written format.

- When too much text is presented on the screen, it is better to use some techniques such as mouse-over in order to make text fit the screen.

- Put all related text in one place.

- If there is a question or activity to be answered, the feedback text must be placed on the same screen to allow a quick comparison without paging back.

- If there are hyperlinks that give information of the same presented text or material, they should be opened or minimized on the same screen.

- It is better to present text using conversational style rather than formal style if applicable (i.e. it depends on learner experience and age).

- Remove unnecessary detailed text.

- Highlight necessary and relevant material using headings, bold, underline, capital letters, large fonts, colors, and arrows.

\section{How to Present Images or Illustrations?}

Not all images or illustrations give a good result in learning; they can enhance learning only if they are presented in a task-appropriate way that may help in solving future tasks [38]. As a conclusion to what have been studied by researchers on the principles of multimedia learning, the presentation of images or illustrations should be provided using the guidelines, which are presented below.

- Present images or illustrations that have the ability to cover all the needed material with a spoken text rather than a written on-screen text.

- Reduce the size of the image if it is too large.

- Avoid unnecessary images or illustrations that do not add knowledge.

\section{How to Present Audio?}

Audio is one of the most powerful tools in multimedia learning it is a solution for presenting text in a way that distributes load, which occurs on the visual channel of working memory. Below are some guidelines for presenting audio in a content environment.

- Audio must be presented in sync with the presented image, animation, or video.

- Provide narrated form of on-screen text when there is no other kind of visuals on the screen.

- The audio format must be recorded with the same language as learners.

- It is better to present audio using conversational style rather than formal style.

- Use human-voice rather than machine-voice.

- Omit any background music or sound that is not related to the course content.

- If an audio text is very difficult to understand, and it was presented with a picture or a visual, it is more effective to present written text rather than audio in unlimited time constraints.

\section{How to Present Animation or Video?}

As stated in [39], animation is one of the exciting pictorial forms of presentation. It has a great power to improve human learning when the goal is to support deep understanding.

Bouki [40] stated that learning through videos lead to a more efficient learning. However, not all "instructional videos" have a "teaching" potential. Videos that are designed without focusing on learning purposes and the principles of cognitive theory specially the redundancy principle, could easily fail. Below are some guidelines for designing animation or video contents.

- Use animation in presenting functions that reveal relationships that are not visible.

- Use videos in presenting an interpretive function and revealing relationships that cannot be brought out to the learners in where they exist.

- Use animation to provide understanding of causeeffect relation-ships.

- Avoid any additional extraneous visuals that are not useful for understanding the material.

- Give the learner control over the pace of the animation or video.

- Provide some arrows or other kinds of symbols.

- Alter the brightness of an object inside an animation to direct learners' attention to a specific point.

\section{b) Map Educational Scenarios to Educational}

Objectives

According to what had discussed before, and the guidelines that were generated from the principles of the cognitive theory it is time to build a useful storyboard. A storyboard is a visual organizer of what an educational content may contain. It visualizes the learning content and its appearance on a web-environment before taking development actions. It represents a step-by-step guide for producing learning content. It gives the developers exact information on how to develop each screen of the educational content. A good storyboard contains screen information, audio instructions, graphics instructions, video instructions, on-screen texts, navigation instructions, and interactivity instructions.

\section{3) Implementation}

The third step in the development lifecycle of an educational electronic content is the implementation phase. This phase includes preparing and integrating media elements. Preparing media elements is done referring to the prepared storyboard in the design phase. From the storyboard, the voice-over text is recorded, the images, illustrations, animations and videos are produced, and the activities/assessments are developed.

Successful implementation of an e-content can only be achieved by integrating the interrelated media elements, which are prepared, based on the guidelines discussed in the design phase and referring to the prepared storyboard.

\section{4) Evaluation}

The last step in the development lifecycle of an educational electronic content is the evaluation phase. The main aim of evaluation is to obtain an indication of the quality of e-content and to collect data in order to improve its design. The evaluation of an e-content should be objectives-oriented that is -the stated goals and objectives of the 
learning content should be actually been achieved and if not it asks why they are not achieved [40]. In addition, the developed e-content should be educational, scientific, and usable.

A deeper look at the design phase of the course content in the e-content development criteria may help in a deeper understanding of how to apply the cognitive theory of multimedia learning in the development of e-contents for teaching computer programming. As a conclusion, the principles that can be applied while presenting a computer programming content are listed in Table II below.

TABLE II.

THE PRINCIPLES THAT CAN BE APPLIED WHEN PRESENTING COMPUTER PROGRAMMING CONTENTS

\begin{tabular}{|l|l|}
\hline Presented Part & \multicolumn{1}{|c|}{ Multimedia Principles } \\
\hline Overall Content & $\begin{array}{l}\text { Navigational principle, sitemap principle, split- } \\
\text { attention principle, redundancy principle, coherence } \\
\text { principle, image principle, voice principle, and } \\
\text { modality principle }\end{array}$ \\
\hline $\begin{array}{l}\text { Before presenting } \\
\text { the related materi- } \\
\text { al }\end{array}$ & Pre-training principle \\
\hline $\begin{array}{l}\text { Learning Objec- } \\
\text { tives/Summary }\end{array}$ & Segmenting principle and personalization principle \\
\hline $\begin{array}{l}\text { Integrated Multi- } \\
\text { media Elements } \\
\text { (Text, Audio, } \\
\begin{array}{l}\text { Images, Anima- } \\
\text { tion) }\end{array}\end{array}$ & $\begin{array}{l}\text { Multimedia principle, segmenting principle, signal- } \\
\text { ing principle, spatial-contiguity principle, temporal- } \\
\text { contiguity principle, personalization principle, } \\
\text { animation and interactivity principles, and cogni- } \\
\text { tive aging principle. }\end{array}$ \\
\hline $\begin{array}{l}\text { Exam- } \\
\text { ples/Questions or } \\
\text { Interactivities }\end{array}$ & $\begin{array}{l}\text { Worked-out examples principle, self-explanation } \\
\text { principle, guided discovery principle, animation } \\
\text { and interactivity principles, and collaboration } \\
\text { principle. }\end{array}$ \\
\hline
\end{tabular}

\section{THE APPLIED SCIENTIFIC EXPERIMENT}

Two online contents were developed for teaching 'FOR loop' in QuickBasic for secondary school students. The course was developed based on 'computer curriculum Level III', that is approved by the Jordanian government using tools like Lectora, Flash, PHP, and MySQL. Actually, there are several reasons for choosing 'FOR loop' for these e-contents. One of the most important reasons is that some secondary school students feel that this lesson is not understandable and feel afraid of solving the problems related to this topic. In addition, bugs with especially loops are common, and updating loop variables in "for" loops, are difficult for learners. An experimental treatment was conducted to (98) Secondary School Scientific Section students at Jubilee Centre for Excellence in Education/Jordan. The research sample was divided into two different groups; the first experimental group studied computer programming from an e-content, which was developed using the proposed framework (BPF), and the second group studied from another e-content, which is not based on the proposed framework (NBPF).

The research hypothesis assumes that designing and developing an e-content based on the cognitive theory of multimedia learning could possibly help in reducing the cognitive overload associated with learning programming and will significantly improve students' learning.

\section{STUDY SAMPLE}

Theresearchsample consisted of (98) eleventh grade female and male students studying at the Jubilee Center for Excellence in Education, which is one of the secondaryschools in Amman/Jordan.These students studied QuickBasic programming language as a part of computer curriculum for the scholastic year 2014.

As they do not have any previous knowledge about programming, they were divided into two groups by looking into their last semester scores in computer curriculum as follow:

- First experimental group learned Quick Basic programming language using an e-Learning environment program which is Based on the Cognitive Theory of Multimedia Learning (BPF), the sample consisted of (25) male and (24) female, and taught at the school's computer lab through the designed and developed website.

- Second experimental group learned QuickBasic programming language using an e-Learning environment program which is Not Based on the Cognitive Theory of Multimedia Learning (NBPF), the sample consisted of (28) male and (21) female students, and taught at the school's computer lab through the designed and developed website.

The stratified sample method had been selected to choose the study sample because of the heterogeneity in the study population in terms of the academic achievement.

\section{DATA ANALYSIS}

A statistical treatment was conducted to analyze the results of the applied experiment using SPSS in order to suggest clear guidelines for e-content designers and developers in the light of the study's results and to prove the research hypothesis. Table III below summarizes the experimental results of the study, the means and the standard deviation.

TABLE III.

EXPERIMENTAL RESULTS

\begin{tabular}{|c|l|c|c|c|c|}
\hline & $\begin{array}{c}\text { Con- } \\
\text { tent_Type }\end{array}$ & N & Mean & $\begin{array}{c}\text { Std. Devi- } \\
\text { ation }\end{array}$ & $\begin{array}{c}\text { Std. Error } \\
\text { Mean }\end{array}$ \\
\hline \multirow{2}{*}{ Pre_Test } & BPF & 49 & 3.576 & .3437 & .0491 \\
& NBPF & 49 & 3.655 & .3354 & .0479 \\
Post_Te & BPF & 49 & 11.979592 & 2.7117783 & .3873969 \\
st & NBPF & 49 & 9.816327 & 3.3271201 & .4753029 \\
\hline
\end{tabular}

A quick glance at table III implies that the students who studied from the e-content, which is based on cognitive theory achieved better than the students who studied from the other e-content, which is not based on cognitive theory. Although, the GPA (Pre-Test) of the students who studied from BPF was less than the GPA of the students who studied from NBPF, but the achievement of BPF students was greater than the achievement of NBPF students. However, the hypothesis could not be proven using just the means of the results, other kinds of tests may be used to confirm the previous results. 
A T-Test was applied to analyze the GPA for all students in order to make sure of Group Equity as shown in Table IV below.

TABLE IV.

T-TEST FOR GROUP EQUALITY

\begin{tabular}{|c|c|c|c|c|c|c|c|}
\hline & \multicolumn{2}{|c|}{$\begin{array}{c}\text { Levene's } \\
\text { Test for } \\
\text { Equality of } \\
\text { Variances }\end{array}$} & \multicolumn{5}{|c|}{ t-test for Equality of Means } \\
\cline { 2 - 7 } & $\boldsymbol{F}$ & Sig. & $\boldsymbol{t}$ & $\boldsymbol{d f}$ & $\begin{array}{l}\text { Sig. (2- } \\
\text { taile-d) }\end{array}$ & \multicolumn{2}{|c|}{$\begin{array}{c}\text { 95\% Confidence } \\
\text { Interval of the } \\
\text { Difference }\end{array}$} \\
\hline $\begin{array}{c}\text { Equal } \\
\text { vari- } \\
\text { ances } \\
\text { assumed }\end{array}$ & .996 & .321 & -1.160 & 96 & .249 & -.2158 & .0566 \\
$\begin{array}{c}\text { Pre } \\
\text { Test Equal } \\
\text { vari- } \\
\text { ances } \\
\text { not } \\
\text { assumed }\end{array}$ & & & -1.160 & 95.943 & .249 & -.2158 & .0566 \\
\hline
\end{tabular}

Since the p-value is 0.321 , which is greater than 0.05 (Alpha Value), it can be concluded that there is no statistically significant difference at the significance level 0.05 between the students in both groups, which means that the two groups are almost equal.

In this case, the two samples means are compared to see if they are significantly different and to prove the given hypothesis. In this study, Hypothesis 0 (H0) assumes that the mean value of post-test scores for students who studied through BPF is equal to the mean value of post-test scores for students who studied through NBPF. Hypothesis A (HA) assumes that the mean value of post-test scores for students who studied through BPF is not equal to the mean value of post-test scores for students who studied through NBPF. Table V shows two-tailed test with alpha value $=0.05$ to compare the mean values of post-test scores for two independent groups.

TABLE $V$.

INDEPENDENT SAMPLES T-TEST

\begin{tabular}{|c|c|c|c|c|c|c|c|}
\hline & \multicolumn{2}{|c|}{$\begin{array}{c}\text { Levene's } \\
\text { Test for } \\
\text { Equality of } \\
\text { Variances } \\
\end{array}$} & \multicolumn{5}{|c|}{ t-test for Equality of Means } \\
\hline & \multirow[t]{2}{*}{$F$} & \multirow[t]{2}{*}{ Sig. } & \multirow[t]{2}{*}{$t$} & \multirow[t]{2}{*}{$d f$} & \multirow[t]{2}{*}{$\begin{array}{l}\text { Sig. (2- } \\
\text { tailed) }\end{array}$} & \multicolumn{2}{|c|}{$\begin{array}{l}\text { 95\% Confidence } \\
\text { Interval of the } \\
\text { Difference }\end{array}$} \\
\hline & & & & & & Lower & Upper \\
\hline $\begin{array}{l}\text { Equal } \\
\text { variances } \\
\text { assumed } \\
\text { Post } \\
\text { Test Equal } \\
\quad \text { variances } \\
\quad \text { not } \\
\quad \text { assumed }\end{array}$ & 1.644 & .203 & 3.528 & 92.247 & .001 & .9454813 & 3.3804171 \\
\hline
\end{tabular}

In this case, the $\mathrm{P}$ value of the $\mathrm{F}$ test is greater than the alpha value 0.05 , so, it is recommended to look into the 'Equal Variances Assumed' row. Moreover, by using the top row of information the $\mathrm{P}$ value of this t-test is $(0.001)$, which is less than the alpha value; which means that $\mathrm{H} 0$ could be ignored, so HA is proved.

\section{A. Reliability of the exam}

The purpose of this test is to check the reliability of the post-test by comparing the number of correct answers for the questions at the same level of difficulty in the given exam.

The post-test contained six questions and had been given to both experimental groups. Table VI shows the number of students who answered each questioncorrectly.Question 1 is not included within the post-test results frequencies because it is a multi-answer question.

TABLE VI.

Post-Test Results FREQuenCIES

\begin{tabular}{|cc|c|c|c|}
\hline \multirow{2}{*}{ SPostTestResults } & \multicolumn{2}{|c|}{ Responses } & \multirow{2}{*}{$\begin{array}{c}\text { Percent of } \\
\text { Cases }\end{array}$} \\
\cline { 2 - 4 } & & $\boldsymbol{N}$ & Percent & \\
& Q2 & 69 & $20.5 \%$ & $71.1 \%$ \\
& Q3 & 58 & $17.2 \%$ & $59.8 \%$ \\
& Q4 & 80 & $23.7 \%$ & $82.5 \%$ \\
& Q5 & 52 & $15.4 \%$ & $53.6 \%$ \\
& Q6 & 78 & $23.1 \%$ & $80.4 \%$ \\
Total & & 337 & $100.0 \%$ & $347.4 \%$ \\
\hline
\end{tabular}

For reliability purposes, questions 'two' and 'six' are at the same level of difficulty, format and tricks.Inaddition,questions 'three' and 'five' are at the same level of difficulty, format and tricks. So,a student who is able to answer question 'two' is also able to answer question 'six' and a student who is able to answer question 'three' is able to answer question 'five'. Therefore, the total number of students who answered question 'two' is ' 69 ' in comparison with ' 78 ' which is the total number of students who answered question 'six' thus the difference between the two groups is ' 9 ' which is not possibly a significant difference between the scores. In addition, the total number of students who answered question 'three' is ' 58 ' in comparison with ' 52 ' which is the total number of students who answered question 'five' thus the difference between the two groups is ' 6 ' which is not possibly a significant difference between the scores.

A split-half reliability test is conducted to ensure the reliability of the exam. The questions that purport to measure the same construct are randomly divided into two sets, and each randomly divided half's average score is calculated and compared with the other half's score. See Fig. 3 below, the average scores for the randomly divided samples are almost the same. Therefore, we can assure the reliability of the test.

\begin{tabular}{|l|c|}
\hline Question 2 =69 & Question 3 $=58$ \\
\hline Average Number of Students $=(69+58) / 2 \approx 64$ \\
\hline \multicolumn{1}{|c|}{$\begin{array}{l}\text { The Average of the two } \\
\text { randomly divided sample } \\
\text { questions is almost the same }\end{array}$} \\
\begin{tabular}{|c|c|}
\hline Average Number of Students $=(52+78) / 2=65$ \\
\hline Question 5 $=52$ & Question $6=78$ \\
\hline
\end{tabular}
\end{tabular}

Figure 3. Split-Half Reliability Test

The previous results show that the average degrees for the students who studied through the e-content that is based on the proposed framework are higher than the 
average degrees for the students who studied through the e-content that is not based on the proposed framework. In addition, the reliability test shows that students' scores are reliable and could be used to prove the given hypothesis. Moreover, there is no statistically significant difference at the significance level 0.05 between the students in both groups, which means that the two groups are almost equal.

\section{B. The Effect of Applying the Proposed Framework on the Experimental results}

It could be seen from Table VII below the improvement percentage for each question in the given post-test for the students who studied through BPF in comparison with the students who studied through NBPF.

TABLE VII.

POST-TEST QUESTIONS ANALYSIS

\begin{tabular}{|c|c|c|c|}
\hline & $\begin{array}{c}\text { Number of Cor- } \\
\text { rect Answers } \\
\text { (BPF) }\end{array}$ & $\begin{array}{c}\text { Number of Cor- } \\
\text { rect Answers } \\
\text { (NBPF) }\end{array}$ & $\begin{array}{c}\text { Improvement } \\
\text { Percentage (\%) }\end{array}$ \\
\hline Q1 & 36 & 28 & $\mathbf{2 9 \%}$ \\
\hline Q2 & 37 & 32 & $\mathbf{1 5 \%}$ \\
\hline Q3 & 31 & 27 & $\mathbf{1 5 \%}$ \\
\hline Q4 & 45 & 35 & $\mathbf{2 2 \%}$ \\
\hline Q5 & 32 & 20 & $\mathbf{6 0 \%}$ \\
\hline Q6 & 43 & 36 & $\mathbf{1 9 \%}$ \\
\hline
\end{tabular}

The main reason behind this difference between results is the use of the proposed framework in presenting each concept, which is actually affected students' answers to each question. For example, the information that belongs to question number 'one' was presented in BPF using mouse-over technique to reduce the cognitive overload on the visual channel by hiding the huge amount of text and viewing it only when needed and to keep the information of the same concept in one place in order to keep the media elements continuous. Moreover, the information was presented using two kinds of media; written and spoken text synchronously, to let the learners make integrations between what they are viewing and what they are hearing, in order to enhance their understanding. The information was also presented using some principles such as multimedia principle, segmenting principle, signalling principle, spatial-contiguity principle, temporal-contiguity principle, animation and interactivity principle, and cognitive aging principle.

The information that belongs to question number 'two' was presented in BPF using an example and an interactivity in order to try some answers and finally find a conclusion. This type of presentation is called discovery learning, where students participate as thinkers in order to build knowledge in their memory. A feedback is provided for the students to check their answers and try to find the final correct solution. Moreover, worked-out examples principle and self-explanation principle were applied to present the content that belongs to the corresponding question.

The information that belongs to question number 'three' was presented in BPF using images and audio formatted text, because as mentioned before in the proposed framework, the use of words and graphics together in any presentation is better than using words alone. The principles that were applied for presenting this information are multimedia principle and guided discovery principle.
The information that belongs to question number 'four' was presented in BPF using an animation, which presents a step-by-step phenomenon in sync with audio formatted text to enhance student understanding of that phenomenon and to reduce the cognitive overload on their auditory and visual channels. The principles that were applied for presenting this information are multimedia principle, segmenting principle, signalling principle, spatial-contiguity principle, temporal contiguity principle, animation and interactivity principle, and cognitive aging principle.

The information that belongs to question number 'five' was presented in BPF using a game-like exercise to increase students' motivation while learning a difficult concept. The principles that were applied for presenting this information are worked-out examples principle, guideddiscovery principle, self-explanation principle and interactivity principle. That is why there is a huge improvement percentage between the two groups.

Finally, the information that belongs to question number 'six' was presented in BPF using written and spoken text synchronously and concluded with an activity in which the student can write some codes and try to find answers. The learning process was guided through some instructions on what to use, and how to use some statements. It also takes some information from the first page of the title, which provides a matching question in order to review previously studied concepts. This kind of teaching methods is known as inquiry learning. The principles that were applied for presenting this information are guided discovery principle and self-explanation principle.

It is clear from the previous results that the e-content, which was developed using the proposed framework, enhanced the achievement of Secondary School students at the Jubilee Center for Excellence in Education in QuickBasic programming language in comparison with the e-content that was developed without using the proposed framework and this proves the given hypothesis.

\section{DISCUSSION OF THE RESULTS}

The analysis of the post-test results show that the students who studied through BPF had improved their academic achievement by $26.7 \%$. Which means that there is significant difference between the average score of the students who studiedQuickBasic Programming Language through the e-content, which is based on the cognitive theory and the students who studied QuickBasic Programming Language through the e-content, which is not based on the cognitive theory.

We can answer the Research Question now according to the previous discussion. The use of the cognitive theory of multimedia learning increased the achievement of the $11^{\text {th }}$ grade students in this QuickBasic Programming Language program and we can attribute this result to the following reasons:

- Employing multimedia elements properly in the educational process through applying the cognitive theory has improved students' ability to comprehend, and helped them in achieving higher scores.

- Applying the cognitive theory in the e-content reduced the extraneous load on the working memory, managed intrinsic load and helped students create a permanent store of knowledge. 


\section{CONCLUSION}

Success in e-learning involves a broad understanding of content development processes. Recent content developments include the growing importance of dynamic and interactive representations of multimedia elements [30]. The process of developing an effective e-content is often performed by following some guidelines. For this reason, this study tried to enhance the quality of learning by integrating the cognitive theory of multimedia learning within a framework to give clear guidelines for the development of educational e-contents. Characteristics of human cognition were incorporated into the proposed framework because any instruction, that proceeds without taking constraints in human cognition into account, is likely to be limited in its effectiveness.

Different theories of multimedia learning were integrated to build an effective research base to enhance learning computer programming and reduce the cognitive overload which happens due to the nature of the subject and poor instructional formats.

A strictly scientific experiment was conducted to determine whether the use of cognitive theory in e-contents in specific population could enhance student learning of computer programming. Two e-contents were developed for teaching a 'FOR loop' in QuickBasic for secondary school students. The level of expertise in the field of computer programming of each student was taken from previous tests in order to distribute the students equally into two matching groups. The course material was developed using Lectora, Flash, PHP, and MySQL. At the end of the lesson in each e-content, a post-test was given to help determine the achievement of each student.

The results, which were analyzed using SPSS showed that adopting the cognitive theory for the developed econtent had a more positive effect on student academic achievement than the standard e-contents because student memory is managed correctly to avoid unnecessary cognitive processes.

\section{FUTURE WORK}

The work described in this study has been concerned with designing an e-content development framework, which is based on the cognitive theory of multimedia learning for enhancing the quality of learning. A new framework consisting of such components was proposed to give e-learning designers and developers some guidelines for developing e-learning contents. While this study has demonstrated the potential of applying the cognitive theory of multimedia learning in e-contents according to our population and experiment, many opportunities for extending the scope of this study remain. Therefore, the following points could be stated as future work:

- Conducting further studies by using the proposed framework for other materials and for wider population.

- Getting into much detail when implementing the user interface and the learning environment.

- Conducting studies by applying the proposed framework to other scholastic education stages.

- Dealing with each learner alone by providing a log file for every learner in order to highlight his weak and strength points and guide him throughout the learning process.
- Enhancing learner-learner and learner-instructor interactions by integrating the developed e-content with social networks.

\section{REFERENCES}

[1] I. G.Alemany, and T. M.Majós, "Strategies to regulate content development and interactivity in the classroom,"European journal of psychology of education, Springer, 15(2), 2000, pp.157-171.

[2] L. Thompson, R.Lamshed, and A. F. L.Framework, "E-learning within the building and construction and allied trades," 2006.

[3] A.Nagy, "The impact of e-learning," In E-Content, Springer Berlin Heidelberg, 2005, pp.79-96. http://dx.doi.org/10.1007/3540-26387-X 4

[4] A.Zerfaß, and B.Hartmann, "The Usability Factor: Improving the Quality of E-Content," In E-Content, Springer Berlin Heidelberg, 2005, pp.165-182. http://dx.doi.org/10.1007/3-540-26387-X 9

[5] F. Bate, I. Robertson, and L.Smart, "Exploring educational design: A snapshot of eight case studies using e-learning in Australian VET," 2003.

[6] M. W. Cronin, and S. L.Myers, "The effects of visuals versus no visuals on learning outcomes from interactive multimedia instruction," Journal of Computing in Higher Education,Springer, 8(2), 1997, pp.46-71. http://dx.doi.org/10.1007/BF02948602

[7] S. L.Muthukumar, "Creating interactive multimedia-based educational courseware: cognition in learning,"Cognition, Technology \& Work, Springer, 7(1), 2005,pp.46-50. http://dx.doi.org/10.1007/ s10111-004-0171-1

[8] T. S. Song, Y. C.Choy, and S. B.Lim, "A multimedia contents development and implementation model based on computer graphics courseware," In Technologies for E-Learning and Digital Entertainment, Springer Berlin Heidelberg, 2006, pp.301-310. http://dx.doi.org/10.1007/11736639_39

[9] C. Roels, and A. Gourdain, "Is it Possible to Conciliate "eLearning", "Learning By Doing" and "Cross Cultural" Approaches when Learning New Technologies?," In Multimedia and EContent Trends, Vieweg+Teubner, 2009, pp. 147-165.

[10] R. E. Mayer, "Introduction to Multimedia Learning," In: Mayer, E. (Ed), The Cambridge handbook of multimedia learning, 2005, pp.1-16. http://dx.doi.org/10.1017/CBO9780511816819.002

[11] J.Sweller, "Implications of Cognitive Load Theory for Multimedia Learning," In: Mayer, E. (Ed), The Cambridge handbook of multimedia learning, 2005,pp.19-30. http://dx.doi.org/10.1017/CBO 9780511816819.003

[12] R. E.Mayer, "Cognitive theory of multimedia learning," In: Mayer, E. (Ed), The Cambridge handbook of multimedia learning, 2005, pp.31-48. http://dx.doi.org/10.1017/CBO9780511816819. 004

[13] S. D.Sorden, "A cognitive approach to instructional design for multimedia learning," Informing Science: International Journal of an Emerging Transdiscipline, 8, 2005, pp.263-279.

[14] J. J. Van Merrienboer, and L.Kester, "The four-component instructional design model: Multimedia principles in environments for complex learning," In: Mayer, E. (Ed), The Cambridge handbook of multimedia learning, 2005, pp.71-93. http://dx.doi.org/10.1017/CBO9780511816819.006

[15] A.Azemi, "Developing an active learning environment with courseware approach," In Frontiers in Education Conference, 1997. 27th Annual Conference. Teaching and Learning in an Era of Change. Proceedings, IEEE, Vol. 3, November 1997, pp.11791184.

[16] N. Mukti, "Courseware development to motivate life-long reading habits," IEEE Multimedia, 8(4), 2001, pp.76-81.

[17] L.Shuguang, L.Pengfei, andB. Lin, "Design and Implementation of the Multimedia CAI Courseware Based on Cognitive Learning Theory," In Education Technology and Computer Science (ETCS), 2010 Second International Workshop, IEEE, Vol. 2, March 2010, pp.803-807.

[18] S.Nie, and Y.Liu, "The Design and Application of Computer Aided Instruction Courseware," In Information Management, Innovation Management and Industrial Engineering (ICIII), 2011 International Conference, IEEE,Vol. 1, November 2011, pp.453455). http://dx.doi.org/10.1109/iciii.2011.115 
[19] K.Kiili, "Towards a participatory multimedia learning model," Education and Information Technologies, Springer, 11(1), 2006, pp.21-32. http://dx.doi.org/10.1007/s10639-005-5711-7

[20] J. D.Fletcher, and S.Tobias, "The multimedia principle," In: Mayer, E. (Ed), The Cambridge handbook of multimedia learning, 2005, pp.117-133. http://dx.doi.org/10.1017/CBO9780511816819. $\underline{008}$

[21] R. E.Mayer, and R.Moreno, "A cognitive theory of multimedia learning: Implications for design principles," Journal of Educational Psychology, Lowell Institute, 91(2), 1998, pp.358-368.

[22] Y. W. Li, N.Mai, and N.Tse-Kian, "Using Mayer's Design Principles in Online Learning Modules: Implementation in a Student Centred Learning Environment," In Informatics and Creative Multimedia (ICICM), 2013 International Conference, IEEE, September 2013, pp.304-309.

[23] I. C. Mow, "Issues and difficulties in teaching novice computer programming," In Innovative Techniques in Instruction Technology, E-learning, E-assessment, and Education, Springer Netherlands, 2008, pp.199-204. http://dx.doi.org/10.1007/978-1-4020$\underline{8739-436}$

[24] P. Dillenbourg, D. Schneider, and P. Synteta, "Virtual learning environments," In Proceedings of the 3rd Hellenic Conference 'Information \& Communication Technologies in Education', 2002, pp.3-18.

[25] L. A. Shepard, "The role of classroom assessment in teaching and learning,"RetrievedfromUniversity of Colorado at Boulder: Retrieved from https://www.cse.ucla.edu/products/reports/TECH517 .pdf, February, $21^{\text {st }}, 2016$

[26] J. R. Hill, D. Wiley, L. M. Nelson, and S.Han, "Exploring research on Internet-based learning: From infrastructure to interactions," Handbook of research on educational communications and technology, 2, 2004, pp.433-460.

[27] S.Barzegar, M.Shojafar, and M. R.Keyvanpour, "Improvement User Interface in Virtual Learning Environment," Digital Society (IJDS), 1(3), 2010,pp.221-229.

[28] N. E.Gronlund, and S. M.Brookhart, Gronlund's writing instructional objectives, Pearson/Merrill Prentice Hall, 2009.

[29] B. L.McCombs, "What do we know about learners and learning? The learner-centred framework: Bringing the educational system into balance,"Educational Horizons, 79, 2001,pp.182-193.

[30] R. C. Clark, and R. E.Mayer, E-learning and the science of instruction: Proven guidelines for consumers and designers of multimedia learning, John Wiley \& Sons, 2011. http://dx.doi.org/10.1002/9781118255971

[31] L. M.Fadel, and M. C.Dyson, "Enhancing interactivity in an online learning environment," In Human-Computer InteractionINTERACT 2007, Springer Berlin Heidelberg, 2007, pp.332-344. http://dx.doi.org/10.1007/978-3-540-74800-7 27

[32] P. E.Steinbronn, and E. M.Merideth, "Perceived utility of methods and instructional strategies used in online and face-to-face teach- ing environments,"Innovative Higher Education, Springer, 32(5), 2008, pp.265-278. http://dx.doi.org/10.1007/s10755-007-9058-4

[33] M. J. Prince, and R. M.Felder, "Inductive teaching and learning methods: Definitions, comparisons, and research bases," Journal of engineering education,John Wiley \& Sons, 95(2), 2006, pp.123138.

[34] T. V.Lyashenko, "Multimedia information technologies in education: Basic concepts, essence, and typology (Review)," Automatic Documentation and Mathematical Linguistics, Springer, 44(4), 2010,pp.206-217. http://dx.doi.org/10.3103/S0005105510040047

[35] P. Zaharias, and A.Poulymenakou, "Implementing the LearnerCentred Design Paradigm for Web-Based Training Curricula," In E-Training Practices for Professional Organizations, Springer US, 2005, pp.325-332.

[36] R.E. Mayer, Multimedia learning (2nd ed.). New York: Cambridge University Press, 2009. http://dx.doi.org/10.1017/CBO 9780511811678

[37] L.Verhoeven, and C.Perfetti, "Advances in text comprehension: Model, process and development," Applied Cognitive Psychology, WileyInterScience, 22(3), 2008, pp. 293-301. http://dx.doi.org/10. 1002/acp.1417

[38] W.Schnotz, "An integrated model of text and picture comprehension,'In: Mayer, E. (Ed), The Cambridge handbook of multimedia learning, 2005,pp.49-69. http://dx.doi.org/10.1017/CBO978051 1816819.005

[39] R. E. Mayer, and R.Moreno, "Animation as an aid to multimedia learning,"Educational psychology review, Springer, 14(1), 2002,pp.87-99.

[40] V. Bouki, D.Economou, and A.Angelopoulou, "Cognitive theory of multimedia learning and learning videos design: the redundancy principle," In Proceedings of the 29th ACM international conference on Design of communication, ACM, October 2011, pp.271278. http://dx.doi.org/10.1145/2038476.2038531

\section{AUTHORS}

Meysun Hamdi completed her master degree in Information Systems at the University of Jordan, Amman 11942, Jordan. Currently working as a locum IT teacher. Prior to this, she worked as a Robotics instructor and an elearning developer for major e-learning projects (e-mail: maisoonhamdi@gmail.com).

Thair Hamtini is an associate professor with the Computer Information Systems Department at the University of Jordan, Amman, Jordan 11942. (e-mail: thamtini@ju.edu.jo).

Submitted 21 October 2015. Published as resubmitted by the authors 23 December 2015. 